\title{
Evaluation of ERA-Interim reanalysis precipitation products using England and Wales observations
}

Article

Accepted Version

de Leeuw, J., Methven, J. and Blackburn, M. (2015) Evaluation of ERA-Interim reanalysis precipitation products using England and Wales observations. Quarterly Journal of the Royal Meteorological Society, 141 (688). pp. 798-806. ISSN 1477870X doi: https://doi.org/10.1002/qj.2395 Available at https://centaur.reading.ac.uk/36723/

It is advisable to refer to the publisher's version if you intend to cite from the work. See Guidance on citing.

Published version at: http://dx.doi.org/10.1002/dj.2395

To link to this article DOI: http://dx.doi.org/10.1002/qj.2395

Publisher: Wiley

All outputs in CentAUR are protected by Intellectual Property Rights law, including copyright law. Copyright and IPR is retained by the creators or other copyright holders. Terms and conditions for use of this material are defined in the End User Agreement.

www.reading.ac.uk/centaur 
Central Archive at the University of Reading

Reading's research outputs online 


\title{
Evaluation of ERA-Interim reanalysis precipitation products using England and Wales observations
}

\author{
J. de Leeuw*a ${ }^{* a}$ J. Methven ${ }^{\mathrm{a}}$ and M. Blackburn ${ }^{\mathrm{b}}$

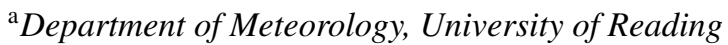 \\ ${ }^{\mathrm{b}}$ National Centre for Atmospheric Science, University of Reading \\ ${ }^{*}$ Correspondence to: Department of Meteorology, University of Reading, PO Box 243, Reading, Berkshire RG6 6BB, \\ UK. E-mail: j.deleeuw@pgr.reading.ac.uk \\ Precipitation forecast data from the ERA-Interim reanalysis (33 years) \\ are evaluated using the daily England and Wales Precipitation (EWP) \\ observations obtained from a rain gauge network. Observed and reanalysis \\ daily precipitation data are both described well by Weibull distributions \\ with indistinguishable shapes but different scale parameters, such that the \\ reanalysis underestimates the observations by an average factor of $22 \%$. The \\ correlation between the observed and ERA-Interim time series of regional, \\ daily precipitation is 0.91. ERA-Interim also captures the statistics of extreme \\ precipitation including a slightly lower likelihood of the heaviest precipitation \\ events ( $>15 \mathrm{~mm} \mathrm{day}^{-1}$ for the regional average) than indicated by the Weibull \\ fit. ERA-Interim is also closer to EWP for the high precipitation events. Since \\ these carry weight in longer accumulations, a smaller underestimation of $19 \%$ \\ is found for monthly mean precipitation. The partition between convective \\ and stratiform precipitation in the ERA-Interim forecast is also examined. In \\ summer both components contribute equally to the total precipitation amount, \\ while in winter the stratiform precipitation is approximately double convective. \\ These results are expected to be relevant to other regions with low orography \\ on the coast of a continent at the downstream end of mid-latitude stormtracks. \\ Copyright (c) 2013 Royal Meteorological Society \\ Key Words: Daily precipitation; rain gauge; rainfall analysis
}

This article has been accepted for publication and undergone full peer review but has not been through the copyediting, typesetting, pagination and proofreading process, which may lead to differences between this version and the Version of Record. Please cite this article as doi: $10.1002 /$ qj. 2395 


\section{Introduction}

Observations of precipitation are sparse compared with the scales that are often characteristic of the field (for example scattered showers, isolated convection or mid-latitude fronts). Rain gauge networks are the only direct means of monitoring precipitation and these vary enormously between countries. Even where gauges are densely distributed, with an average spacing of a few kilometers, there is an issue of representativity relative to the volume averages observed by remote sensing. Indirect measurements from satellites have a better spatial coverage, giving the possibility to obtain precipitation estimates over areas not covered by rain gauges. However, the indirect nature of the observations (mostly cloud-top reflectance and thermal radiance) counteract this advantage, resulting in large variability in skill for the precipitation estimates obtained (Ebert et al. 2007; Yilmaz et al. 2005; Dinku et al. 2007).

Although observations of precipitation are not assimilated directly in the initialisation of numerical weather prediction (NWP) models, the atmospheric state including pressure, temperature, winds and humidity is well represented by global analyses (see for example Dee et al. (2011) for the performance of ERA-Interim or Kistler et al. (2001) for the NCEP-NCAR reanalysis). To the extent that the NWP models used in assimilation are a faithful representation of the atmosphere, forecast fields can be used to estimate quantities such as precipitation. Problems with estimates of the global hydrological cycle (Trenberth and Guillemot 1998; Kobold and Sugelj 2005) from reanalysis have been investigated by many authors. Recently effort has been put into the improvement of the precipitation products derived from reanalysis systems, which has led to significant progress (Balsamo et al. 2010; Sapiano et al. 2008). Most evaluation studies compare reanalysis data with observations that are representative for continental scale areas (e.g. Europe (Zolina et al. 2004) and Africa (Poccard et al. 2000)) or globally (Bosilovich et al. 2011; Simmons et al. 2010). These studies have made broad statements, such as the identification of tropical oceanic regions with the poorest precipitation estimates (Bosilovich et al. 2008).

On the regional scale, Kobold and Sugelj (2005) compared operational ECMWF precipitation forecasts with local gauge data in Slovenia during nine extreme events in 1994 and 1997 and found a general underestimation of 60\%, linking this to the mountainous character of the landscape. Romanou et al. (2010) investigated satellite observations (HOAPS-3) over the Mediterranean and Black seas between 1989 and 2001 and found that ECMWF reanalyses overestimated the mean precipitation estimates. Szczypta et al. (2011) compared the ERA-Interim precipitation product with precipitation observations (GPCP and GPCC) over France and found an average 30\% underestimation by the ECMWF reanalysis between 1991-2008 for monthly precipitation. Their results show that there is a large variability in the model skill for different regions, but they did not evaluate the representation of precipitation across the range of intensities from dry days to extremely heavy (regionally aggregated) precipitation.

Dee et al. (2011) investigated the precipitation product of ERA-Interim over the UK by selecting four $1^{\circ} \times 1^{\circ}$ boxes located over the British Isles and compared it with (gauge based) GPCC data of the same resolution. They found that for this small sample, the monthly precipitation in the reanalysis strongly correlates with the GPCC data, but that it has a general tendency to underpredict the maximum precipitation. However, their comparison was limited to 4 points and only a qualitative comparison is presented.

This paper aims to investigate the statistical distribution of intensity for regionally-aggregated, daily precipitation and to evaluate the ability of the ERA-Interim system to estimate precipitation across the range from dry days to extreme events. The 33-year re-analysis record is long enough to evaluate the intensity of precipitation events (averaged over the region) including the extreme tails of the distribution (e.g., 120 days above 99th percentile). The region chosen is England and Wales which has a continuous 
80 year daily record from a dense gauge network. A homogeneous record in time has been created for the region by considering changes in observation methods and sites (Wigley et al. 1984a; Gregory et al. 1991; Alexander and Jones 2000; Croxton et al. 2006). The statistics of England-Wales Precipitation (EWP) have been investigated by several authors (Osborn et al. 2000; Mills 2005) in more detail than most regions of the world (see Section 2). The dataset motivates the choice of region. England and Wales are at the downstream end of North Atlantic storm-track and are generally low lying (mostly less than 500m above sea level). Therefore precipitation is dominated by the passage of large-scale weather systems and the results are likely to be relevant for other similar regions at the end of midlatitude stormtracks.

In section 2 , the data and methodology are defined, followed by a short discussion of the diurnal cycle. Comparison of ERA-Interim with observed daily and monthly accumulations is presented in sections 3 and 4 respectively. In section 5 , the partition between the convective and large scale precipitation in the ERAInterim forecast model is examined. Concluding remarks are presented in section 6 .

\section{Data and methodology}

The England and Wales Precipitation (EWP) dataset (Alexander and Jones 2000) contains daily accumulations, spatially averaged over England and Wales. This time series is maintained and updated by the Met Office Hadley Centre and is available from 1931 to the present day (www.metoffice.gov.uk). The England and Wales estimates are based on the weighted contribution of 5 climatological different sub-regions (Wigley et al. 1984b; Wigley and Jones 1987), each of which has at least 7 evenly distributed stations (all regional time series have 715 stations incorporated, depending on the availability of data (Alexander and Jones 2000)).

Daily accumulation at each of the stations is scaled by the ratio of the regional monthly normal to the stations' monthly normal, before combining to form the sub-region estimate. This ensures that it is not weighted towards sites with locally high precipitation (e.g. local orographic effects). In this way, the effects of changing the gauge network has less impact on the sub-region estimates, making them more robust. The sub-region totals are then combined to produce an England and Wales Precipitation average using regression analysis (Wigley et al. 1984b).

Wigley et al. (1984a,b) and Gregory et al. (1991) investigated how well this area-average precipitation measure is able to represent the climatological variability in the England and Wales region, which is important for the comparison with the model. They found that using an average of 35 stations over the region (7 per sub-region) is able to capture at least $86 \%$ of the daily variability of the true area-average signal and more than $90 \%$ for the monthly accumulations. Also Wigley et al. (1984b) showed that, to increase the accuracy of the precipitation estimated derived from the 35 stations by $1 \mathrm{~mm}$, one would have to use approximate 270 stations. Later studies have compared the EWP observations with higher density datasets in the England and Wales region (Croxton et al. 2006; Simpson and Jones 2012), showing marginal improvement of the areal precipitation representation. Simpson and Jones (2012) compared the EWP observations with a newly developed 5-km gridded daily precipitation set by the Met Office Hadley Centre. They found that for $98 \%$ of all the daily observations both datasets agreed within $1 \mathrm{~mm}$ and $90 \%$ within $0.5 \mathrm{~mm}$. This gives confidence that the EWP dataset is a robust estimate of precipitation for the region (e.g. (Mills 2005)). For the purpose of this paper, daily data were selected from 1979 onward, which is the period over which the ERA-Interim forecast products are available.

The EWP observations are compared with the ERAInterim precipitation forecast from the European Centre for Medium-Range Weather Forecasts (ECMWF). The forecast model incorporated in the ERA-Interim reanalysis is based on the ECMWF IFS (Cy31r2) forecast model (for more information see Dee et al. (2011) and references therein), 


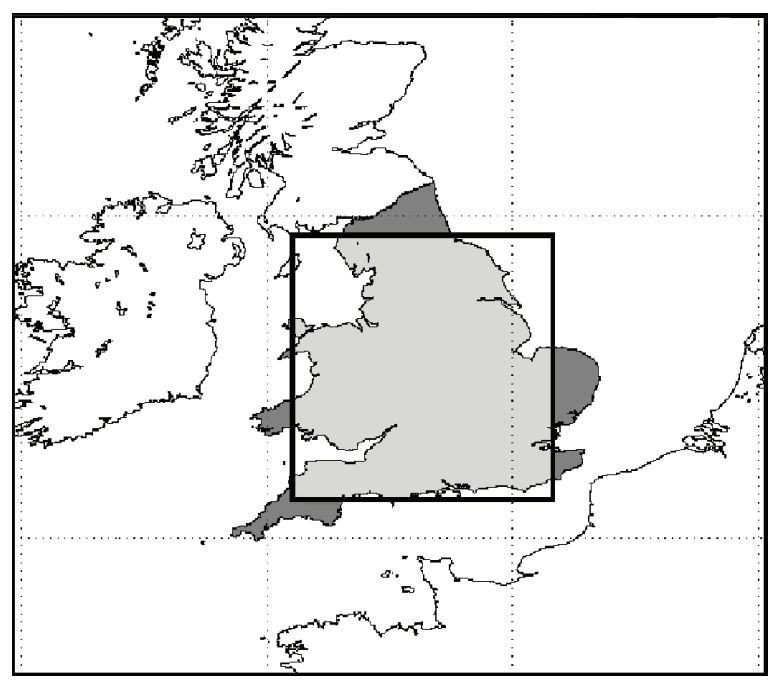

Figure 1. England and Wales (all grey areas) and the box used to find areaaveraged precipitation from the ECMWF reanalysis forecast. The light grey shading is the part of England and Wales captured in the area-average of forecasts, while the dark grey areas are not included.

with a spectral horizontal resolution of T255 $(\sim 80 \mathrm{~km})$ and 60 vertical levels. Precipitation data are retrieved on the model's linear Gaussian grid from January 1979 to December 2011, giving 33 years of data.

The ERA-Interim forecast precipitation is the sum of two components which are computed separately in the model. Large-scale precipitation (from now on referred to as stratiform) originates from the prognostic parametrization of cloud (Tiedtke 1993; Tompkins et al. 2007), while convective precipitation originates solely from the parametrization of convection (Tiedtke 1989; Bechtold et al. 2004). However, the two parametrisations are linked, by detrainment of convective cloud which is one source of condensate of the prognostic cloud scheme. Further information can be found at the ECMWF website (www.ecmwf.int/research/ifsdocs/CY31r1/index.html).

The total precipitation in the reanalysis is averaged over the box depicted in figure 1, for comparison with the EWP observations. This corresponds to 49 grid boxes that are included in the domain given by $\left[50.6^{\circ} \mathrm{N}-54.5^{\circ} \mathrm{N} \times 4.5^{\circ} \mathrm{W}\right.$ $\left.0.7^{\circ} \mathrm{E}\right]$. The box area $\left(151,439 \mathrm{~km}^{2}\right)$ includes most of the England and Wales region and was designed to have a similar area to England and Wales $\left(151,129 \mathrm{~km}^{2}\right)$. Given the resolution of the analysis (including the land-sea mask) and the fact that the observational estimate itself is obtained by combining only 5 sub-regions, it was thought to be less robust to define an irregular set of grid-points. All the model grid points in the domain were combined with equal weight. Changing the domain, either by including or excluding 7 grid boxes to represent the England and Wales area more closely, was found to have a minimal effect on the results. The relations found in all the following sections did not change, although it should be mentioned that some values (e.g. $R^{2}$ in figure 6) did change by several percent.

The EWP daily record represents accumulations from 0900 UTC to the same time the next day (when observers report the measurements). The ERA-Interim forecasts are initialised only twice a day at 0000 UTC and 1200 UTC and the precipitation is accumulated from the beginning of each forecast. Two different methods were used to obtain a daily accumulation of forecast precipitation, as shown in Figure 2. In the first method, the 12 hour forecasts are combined from each initialisation time (represented by the black horizontal lines B+C in Fig. 2). By combining two 12 hour forecasts each day, a daily estimate of the precipitation accumulation from 1200 UTC to 1200 UTC is obtained (bounded by black dashed lines in figure 2).

In the second method, the 6 and 12 hour forecasts are combined. In addition to the accumulations 6 hours into each forecast (lines $\mathrm{P}, \mathrm{Q}$ and $\mathrm{R}$ in figure 2), the accumulations between 0600-1200 UTC and 1800-0000 UTC are calculated using A-P and B-Q respectively. Combining 4 consecutive accumulations ((A-P)+Q+(B$\mathrm{Q})+\mathrm{R}$ ) results in a daily precipitation accumulation running from 0600 UTC (bounded by grey dashed lines in figure 2). All the analysis in this paper has been performed for both accumulation periods and the statistical results were found to be nearly identical. It was decided to show only the results for the 0600 UTC starting point as it has a more natural date labelling (most of the precipitation actually falls on the indicated date).

A threshold of $0.1 \mathrm{~mm}^{\text {day }}{ }^{-1}$ is used to define dry days in the daily time series for both the EWP and ECMWF data. Due to the inclusion of multiple stations, this threshold 


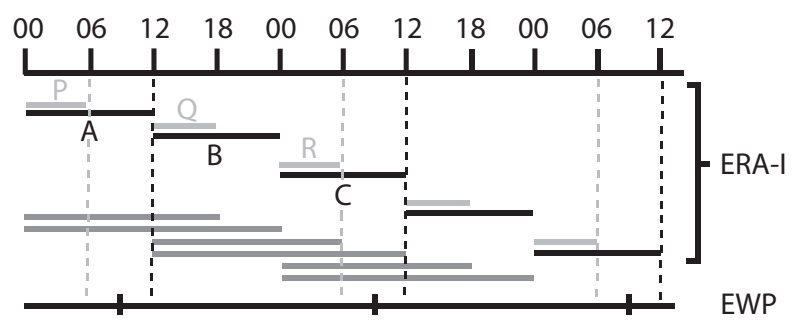

Figure 2. A schematic showing the time line for the retrieved ERA-I forecasts and EWP observations. The light grey and black horizontal lines depict the 6-hour (P, Q and R) and 12-hour (A, B and C) ERA-Interim forecasts respectively. Combining two 12 hour forecasts (lines $\mathrm{B}$ and $\mathrm{C}$ ) will give a daily accumulation (from 1200 UTC) in contrast with the EWP observations accumulated from 0900 UTC each day. Calculating A-P+B+R will give the daily accumulation from 0600 UTC (time window bounded by the grey dashed lines). The dark grey lines represent the longer lead time forecasts used to investigate the spin-up effect (section 3.4), which are combined in a similar fashion to obtain daily accumulations.

is lower than that typically used for individual stations (e.g., $0.3 \mathrm{~mm} \mathrm{day}^{-1}$ in Maraun et al. (2008)). Changing the threshold from 0.1 to $0.3 \mathrm{~mm} \mathrm{day}^{-1}$ barely altered the results.

\subsection{Diurnal cycle}

By combining all the ECMWF forecasts between 1979 and 2011, the average precipitation accumulated over 6 hour intervals was calculated as a function of time of day. Figure 3 presents the 6 hour accumulations as a percentage of daily accumulation.

To minimise the impact of low precipitation days, totals were calculated between 1979 and 2011 for each 6 hour interval and then divided by the total observed precipitation. If there were no dependence on time of day, all 4 intervals would contribute $25 \%$. The composite diurnal cycle is very weak (peak-to-peak amplitude of 1\%). In contrast, Dai et al. (2007) investigated the summer diurnal cycle of precipitation using satellite observations over the midlatitudes and found a maximum during the afternoonevening with a mean-to-peak amplitude of approximately $20-30 \%$ of the daily mean over Western-Europe, while only a weak diurnal cycle $(<10 \%)$ was found during boreal winter.

The weak diurnal cycle for the England and Wales region is perhaps explained by the strong influence Atlantic weather systems all year round, compared with continental regions. Individual seasons (not shown here) show diurnal cycles of similar magnitude, even in summer when convection is more active. When making the partition between convective and stratiform precipitation in the forecast, a very small diurnal cycle is also found for both components (figure 3 ). The convective precipitation shows a weak maximum during the afternoon and a minimum during the early morning. The stratiform precipitation is slightly stronger in the morning.

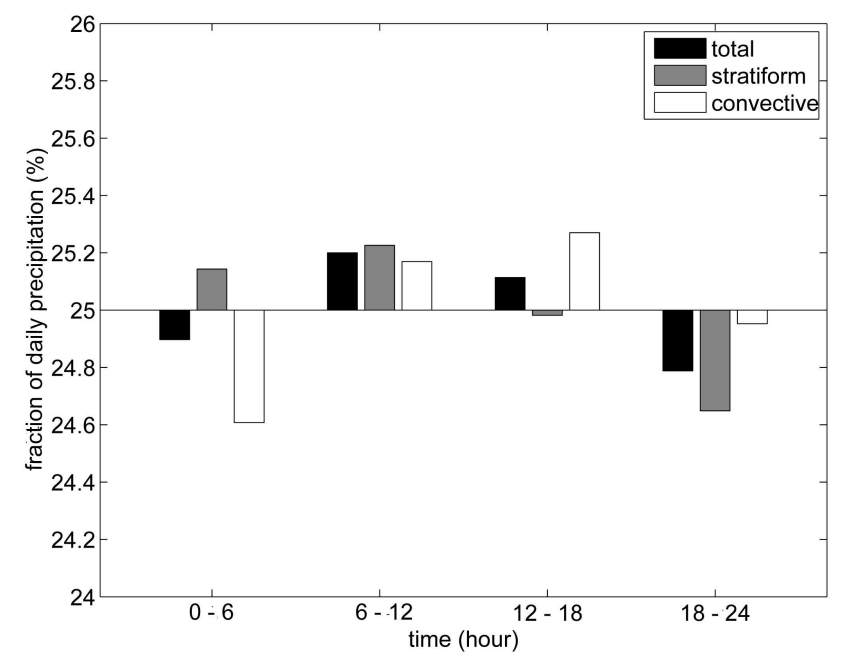

Figure 3. The fraction of daily precipitation (1979-2011) in the ERAInterim precipitation forecast for each of the four 6 hour intervals in the model. Also the diurnal cycle for the convective and stratiform precipitation is shown. On average the precipitation is split as 55\% stratiform and $45 \%$ convective.

\section{Daily Accumulations}

\subsection{Observed rain days}

The contingency Table I shows the skill of ERA-Interim in simulating dry days versus rain days. Out of 293 observed rain days (ORD) per year (1979-2011 average), 284 were captured in the ERA-Interim estimates and 9 were "missed forecasts". There were also 29 "false alarm" forecast rain days for each year on average. The precipitation amounts for the "false alarm" ECMWF forecasts were all small events $\left(<0.5 \mathrm{~mm} \mathrm{day}^{-1}\right)$ and therefore sensitive to the threshold defining "dry days". However, the "false alarms" contribute little to the total precipitation. No significant differences were found for data partitioned by season, indicating that the precipitation forecast shows similar skill throughout the year. 


\begin{tabular}{|c|c|c|c|}
\hline \multicolumn{2}{|c|}{ Annual data } & \multicolumn{2}{c|}{ EWP } \\
\cline { 3 - 4 } \multicolumn{2}{|c|}{} & rain & dry \\
\hline \multirow{2}{*}{ ERA-I } & rain & 284 & 29 \\
\cline { 2 - 4 } & dry & 9 & 43 \\
\hline
\end{tabular}

Table I. Contingency table for rain days $(>0.1 \mathrm{~mm})$ and dry days in the ERA-Interim reanalysis forecast and EWP daily precipitation (19792011). The results are rescaled such that they represent the average number of days per year.

\begin{tabular}{l||c|c|c|} 
& EWP & ERA-I & ERA-I (ORD) \\
\hline Annual & 943 & $82.1 \%$ & $81.2 \%$ \\
DJF & 258 & $82.0 \%$ & $80.5 \%$ \\
MAM & 197 & $87.9 \%$ & $85.5 \%$ \\
JJA & 210 & $84.1 \%$ & $82.3 \%$ \\
SON & 276 & $79.4 \%$ & $78.1 \%$ \\
\hline \# rain days & 293 & 313 & 284 \\
\hline
\end{tabular}

Table II. Precipitation amount (mm) for the observations (EWP) and the fraction (\%) represented by the ERA-Interim reanalysis forecast precipitation falling on all days and solely during the EWP observed rain days (ORD) . The last row shows the average number of days with rain per year in observations, ERA-Interim and their intersection.

Table II shows that the ECMWF model underestimates the total annual precipitation significantly. Although there is a marked seasonal cycle in precipitation, the fractional underestimation is similar for different seasons, although worst in autumn. As seen already in Table I, ERAInterim overestimates the number of rain days. However, the effect of the extra number of rain days on the seasonal accumulation is marginal, as shown by the right column when only data from the Observed Rain Days (ORD) are included in the accumulations.

In order to obtain a consistent comparison, all the following statistics in this paper are calculated using the ECMWF precipitation products only during Observed Rain Days (ORD - as defined by the EWP dataset). This ensures that the extra rain days in the ECMWF forecast (i.e., labelled 'false alarms') do not contribute to the precipitation accumulations shown. The analysis was also performed using all rain days in the ECMWF data and, although numerical values were slightly different, the conclusions from the results would be unchanged.

\subsection{Distribution of daily precipitation intensity}

Analysing the discrete probability distribution of the two daily datasets in more detail shows that both have qualitatively similar, though quantitatively different structure. Both EWP and ECMWF were fitted with a Weibull distribution, as it was found in previous studies that daily precipitation observations are well fitted using this distribution (Burgueno et al. 2005). To investigate how well the observations and ECMWF forecast are represented by the Weibull distribution, cumulative probability plots are drawn in figure 4 . Here the relative position of probability levels on the vertical axis is based on the Weibull function which assures that any Weibull distributed dataset would be represented by a straight line.

The probability plots clearly show that model and observations are both in good agreement with the Weibull distribution, although there are deviations in both tails of the distribution. The largest deviations are found for the "very light' precipitation events $\left(<0.3 \mathrm{~mm} \mathrm{day}^{-1}\right)$, for which the fitted Weibull distributions (dot-dash lines) overestimate the event frequency of both EWP and ECMWF forecast precipitation. The discretisation of the EWP data for light events shows the limited resolution of the observations in the lower end of the precipitation spectrum. For the higher end of the distribution there is a slight overestimation of the event frequency by the best Weibull fit, which results in a broader tail in the Weibull distribution than for the data when considering values larger than 15-20 $\mathrm{mm} \mathrm{day}^{-1}$.

Calculating the corresponding scale and shape parameters of the Weibull distributions shown in figure 4 quantifies the similarity of the two datasets. It is found that both have indistinguishable shapes (parameter values of $0.89 \pm 0.02$ and $0.91 \pm 0.02$ for EWP and ECMWF respectively), but the scale parameter is smaller $(78 \%)$ for the ECMWF forecast (parameter values of $3.03 \pm 0.07$ and $2.36 \pm 0.06$ for EWP and ECMWF respectively). This implies that the ECMWF forecast underestimates the EWP precipitation across the entire precipitation range.

Differences between the two datasets are investigated further using a quantile-quantile plot (qq-plot) (Fig. 5a). This compares the precipitation rates that belong to any probability quantile in the two distributions. If two datasets are selected from the same distribution (same shape, but 

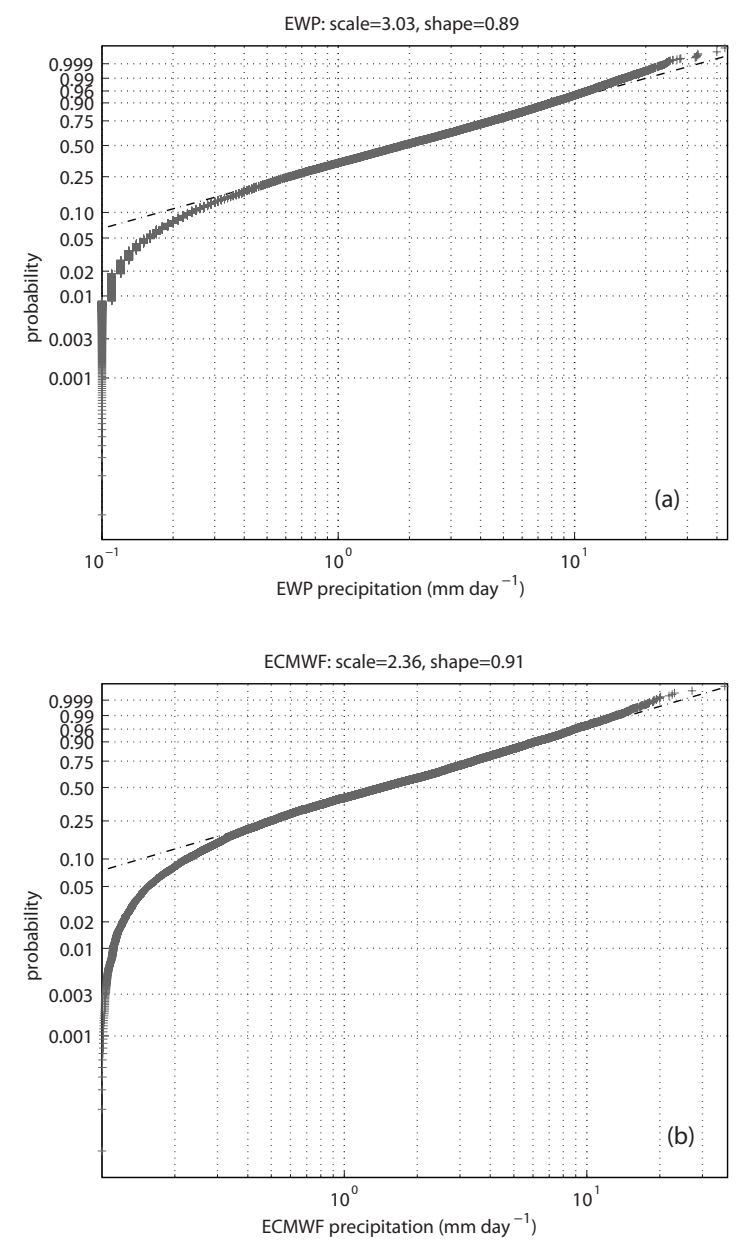

Figure 4. Weibull cumulative probability plots for a) observed EWP and b) ECMWF area averaged precipitation. The plots show the cumulative probability for measuring a certain precipitation amount and are constructed such that the Weibull distribution is represented by a straight line. The best estimates of the shape parameter for the Weibull fit (dashed line) indicates the similarity of the two datasets.

not necessarily the same absolute values), this would be represented by a straight line on a qq-plot. The slope of the qq-plot is $0.782 \pm 0.005$ when using all the data, which indicates that the ECMWF model underestimates the EWP observations on average by $22 \%$ (consistent with the Weibull scale parameters). These results are of similar magnitude to those found in a study over France by Szczypta et al. (2011), who identified a mean underestimation of $30 \%$ when comparing 18 years of ERAInterim precipitation products (1991-2008) with rain gauge observations.

The long ERA-Interim and EWP datasets enables quantification of the extreme tails of the distributions. Figure 5a shows that some small, but statistically significant differences are present in the tails. For the quantiles above 99\%, the ECMWF model shows heavier precipitation relative to the linear fit (dot-dash line). A least square linear fit through the top $10 \%$ events in the qq-distribution shown in figure 5a, gives a slope of $0.827 \pm 0.005$, meaning that the model estimate is slightly closer to the observed EWP in the heaviest precipitation events. This slightly non-linear behavior results in a smaller underestimation in monthly accumulations (discussed later). The difference below the $10 \%$ quantile is due to the occurrence of completely dry days in the ECMWF reanalysis, even though only the statistics for observed rain days $(\mathrm{EWP}>0.1 \mathrm{~mm}$ ) are shown. These are the "missed rain days" occurring at an average of 9 per year (Table I).
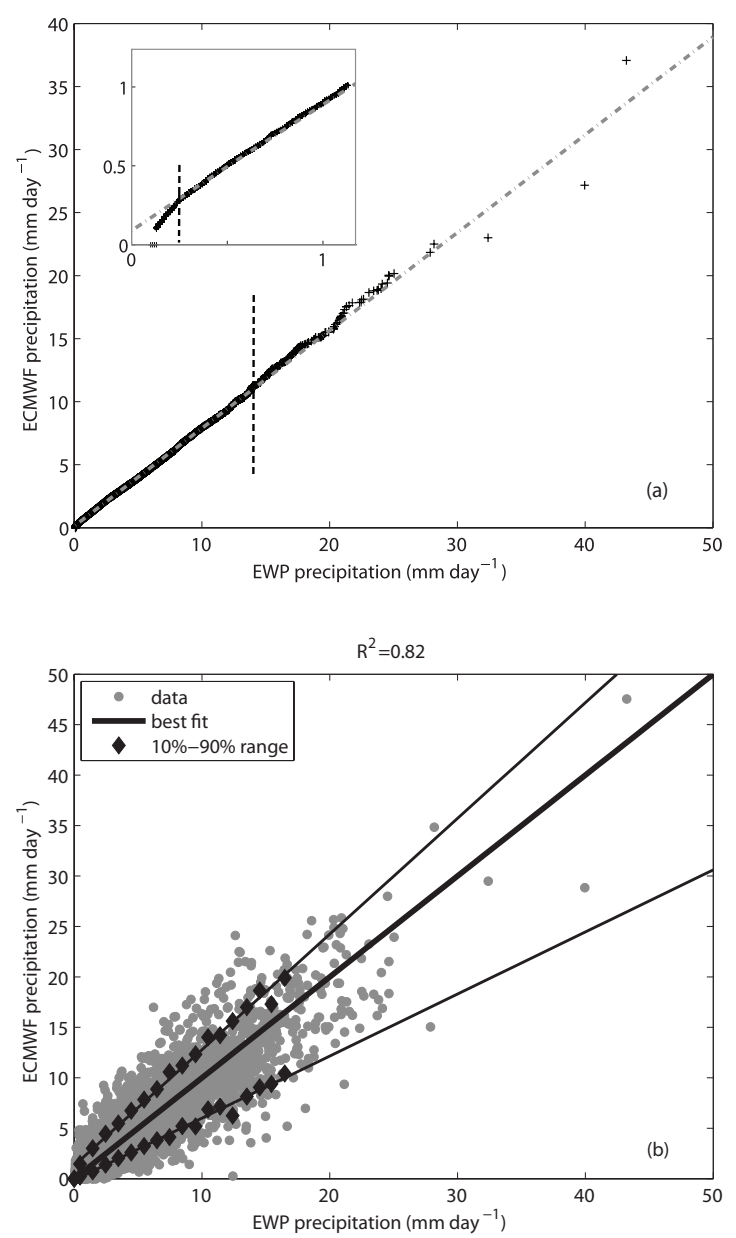

Figure 5. a) A quantile-quantile plot for daily EWP and ECMWF precipitation and the best linear fit to the data. The small insert figure expands the lower end of the qq-plot. The vertical dashed lines indicate the $99 \%$ and $10 \%$ quantiles of the data. b) Scatter plot showing observations (EWP) versus model forecast (ECMWF) for all days after applying the scaling factor. The thick solid line represents the best linear fit (least square method) and the thin solid lines represent the 90th/10th percentile range of the ECMWF forecast data falling within each bin of EWP (bin width 1 $\mathrm{mm}$ day ${ }^{-1}$ ). The percentiles are only shown for EWP bins with greater than 10 events. 
The quantile-quantile comparison re-orders the 2 datasets differently so that the statistics are unaffected by the degree of temporal correlation. A scatter plot (figure 5b) constructed from all available time-points in the 33-year comparison period, after applying the scaling factor to the ECMWF data, shows that all points are scattered around the 1:1 line. This indicates that the underestimation $(0.782 \pm 0.005)$ by the ECMWF forecast model applies throughout most of the precipitation range. The figure also shows the 10th and 90th percentile range of the ECMWF forecast data, calculated within bins for observed EWP values. The percentiles also scale linearly with daily EWP accumulations. The ECMWF re-analysis estimates and observations are strongly correlated $\left(R^{2} \approx 0.82\right)$ such that $82 \%$ of the variance in the comparison is explained by the linear fit.

In summary, ERA-Interim daily precipitation (across England and Wales) is highly correlated with observed EWP and shares almost the same statistical distribution, aside from an underestimation. The underestimation is well described by a single scale factor $(0.78 \%)$ although detailed examination reveals that the underestimation is less marked for the heaviest $10 \%$ of events.

\subsection{Seasonality of ECMWF and EWP}

To investigate the seasonality of the comparison, similar scatter plots for the four different seasons (without the optimal seasonal scaling applied) are shown in figure 6 . There are only small differences in slope between the seasons, so all seasons show a consistent underestimation by the ECMWF model. Based on the $R^{2}$ values (see figure 6) slightly more scatter is observed in summer compared to the other seasons. Possible explanations for this difference might be related to the nature of the precipitation in the different seasons, as will be discussed later.

\subsection{Spin-up effect of the reanalysis forecast}

A drawback of using short forecast lead times is the possible introduction of spin-up errors (Betts et al. 2003), which are mainly due to inconsistencies between the assimilated observations and the model used in the reanalysis at the start of each forecast. For the results already shown, only the first 12 hours of the forecast are used, whereas other studies (Kobold and Sugelj 2005; Szczypta et al. 2011) have used a longer lead time for their analyses. Betts et al. (2009) states that the spin-up of precipitation in ERA-Interim during the first 24 hours of forecasts in mid-latitude continental regions is approximately 5\%. It is unclear to what extent the results of Betts et al. (2009) are applicable to the more maritime UK region, which receives much of its precipitation from Atlantic weather systems.

Therefore, to investigate the effect of forecast lead time on the comparison, the foregoing analysis has been performed for a single year (2007), but based on forecasts with 12-24 hour lead times (see dark grey lines in schematic of figure 2). To quantify the difference between the two forecast lead times, a scatter plot similar to that in figure 5 is constructed for 2007 based on both lead time experiments and shown in figure 7 (no scaling applied). Investigating the least squares linear fit shows that the slope of the forecast with a longer lead time versus observations $(0.81 \pm 0.03)$ is closer to unity than for the short lead time experiment $(0.78$ $\pm 0.03)$. The overall improvement for this single year was in the order of $3 \%$, with some individual outlier days having an increase as large as $70 \%$.

The general bias found here is similar to that found by Betts et al. (2009) and falls within the spread of the best estimate of the short lead time experiment. This indicates that, although some individual events might be strongly affected by spin-up, the results found previously appear to be robust over different lead times and that no significant improvements are expected for even longer lead times.

\section{Monthly Accumulations}

A comparison of the total monthly precipitation data from the ECMWF forecast with EWP is shown in Fig. 8a, after re-scaling the ECMWF forecasts by diving by the factor (0.782) derived from the qq-plot of daily accumulations. 

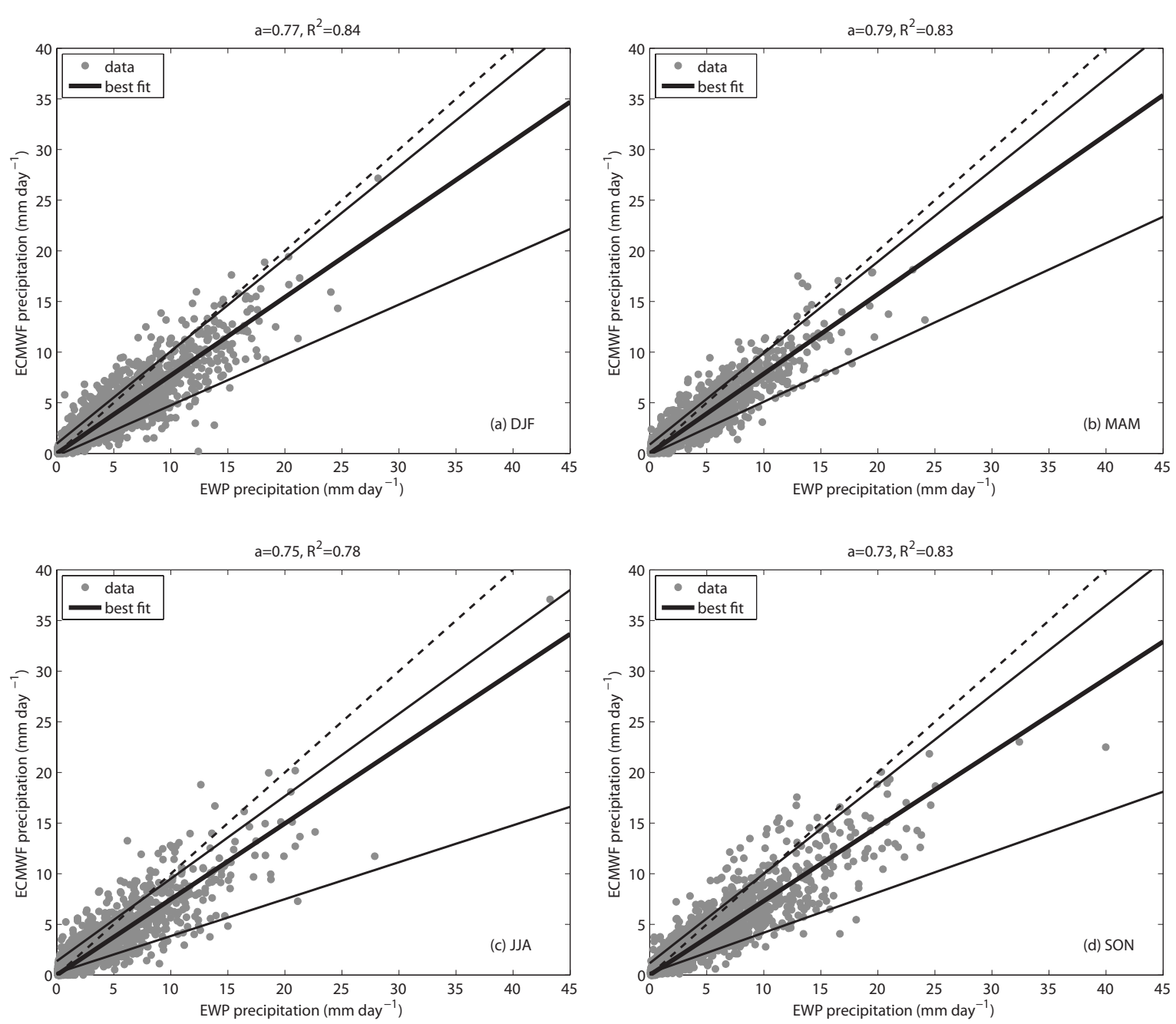

Figure 6. Same as figure $5 b$, but for the four seasons (without scaling the forecast). For clarity the diamonds shown in figure $5 b$ are omitted. The dashed line shows the 1:1 slope. The slope of the linear fit (a) is shown at the top of each panel, together with the correlation squared $\left(R^{2}\right)$.

This correction derived from daily accumulations is too large. Calculating the 10/90th percentiles of the monthly totals shows that the re-scaling also overestimates the most extreme monthly values in both tails of the precipitation distribution. A different scaling factor of $0.812 \pm 0.006$ is obtained from a least squares linear fit to the scatterplot of monthly precipitation accumulations in the two datasets (green curves), instead of the daily values. Using this single monthly re-scaling factor, the ECMWF monthly accumulations fit the seasonal cycle of observed EWP very well with differences in monthly average precipitation rates smaller than $0.05 \mathrm{~mm} \mathrm{day}^{-1}$ on average. The maximum precipitation occurs on average in the months October to December and minimum May to July.
The difference between the scaling factors obtained from daily versus monthly precipitation accumulations is associated with the curvature in the qq-plot (figure 5). ECMWF precipitation is closer to observed EWP for the heaviest daily accumulations, and these high precipitation totals have more weight than light precipitation events in the monthly accumulations. Since only the ORD are included in the comparison, the extra number of rain days in the reanalysis is not responsible for the overestimation found using the daily scaling factor.

\section{Convective and Stratiform precipitation}

The ECMWF forecast model data also gives the opportunity to discuss the separate contributions of the convective and stratiform precipitation components, although it is 


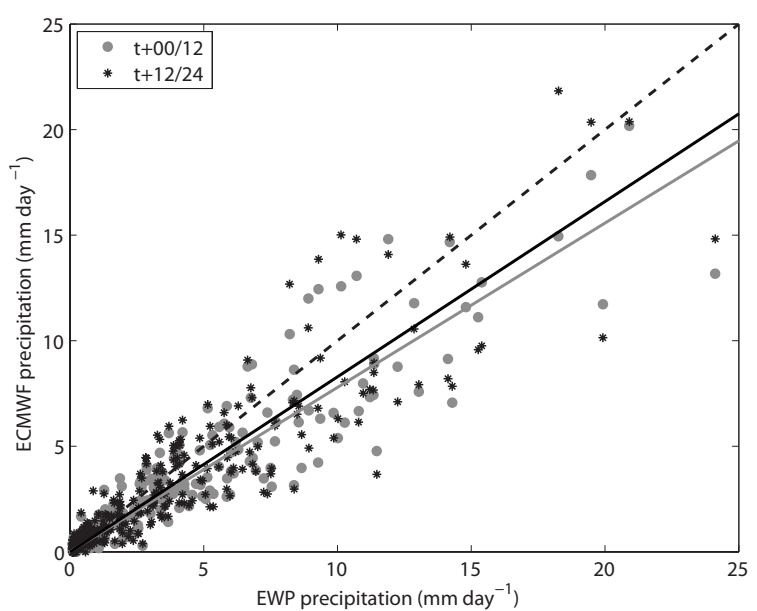

Figure 7. A scatter plot of EWP versus ERA-Interim area averaged daily precipitation amounts in 2007 for two different sets of lead times. The grey dots are obtained using the same method as used in Fig. 5b, and the black dots are obtained using forecasts with lead times that are 12 hours longer. The solid lines represent best linear fit to the data.

recognised that this partition is model dependent. Hand et al. (2004) used detailed observations to estimate this partition for extreme flood events in the UK during the twentieth century. They found that most extreme events occurred in summer, which were dominated by the convective events, while in autumn and winter the stratiform precipitation was most important. Unfortunately such observations (including the type of precipitation) are not available on a daily basis, thereby limiting the possibilities to extend their study to the entire period investigated in this paper. The Hand et al. (2004) study does suggest that there is a seasonal dependency for the two types of precipitation, which is therefore also expected to be present in the ERA-Interim precipitation model.

Figure $8 \mathrm{~b}$ shows that the stratiform precipitation has a strong seasonal cycle with a minimum in May to July, while the convective part shows a minimum in January to March.

As a result the ratio between stratiform and convective precipitation is approximately $2: 1$ in winter, while it is less than $1: 1$ in summer.

There is also a large seasonal cycle in the spread of the convective precipitation, with the largest spread found in summer. Together with figure 6 , this suggests that the comparison between EWP and ECMWF is slightly worse in seasons with more convective activity, which could relate
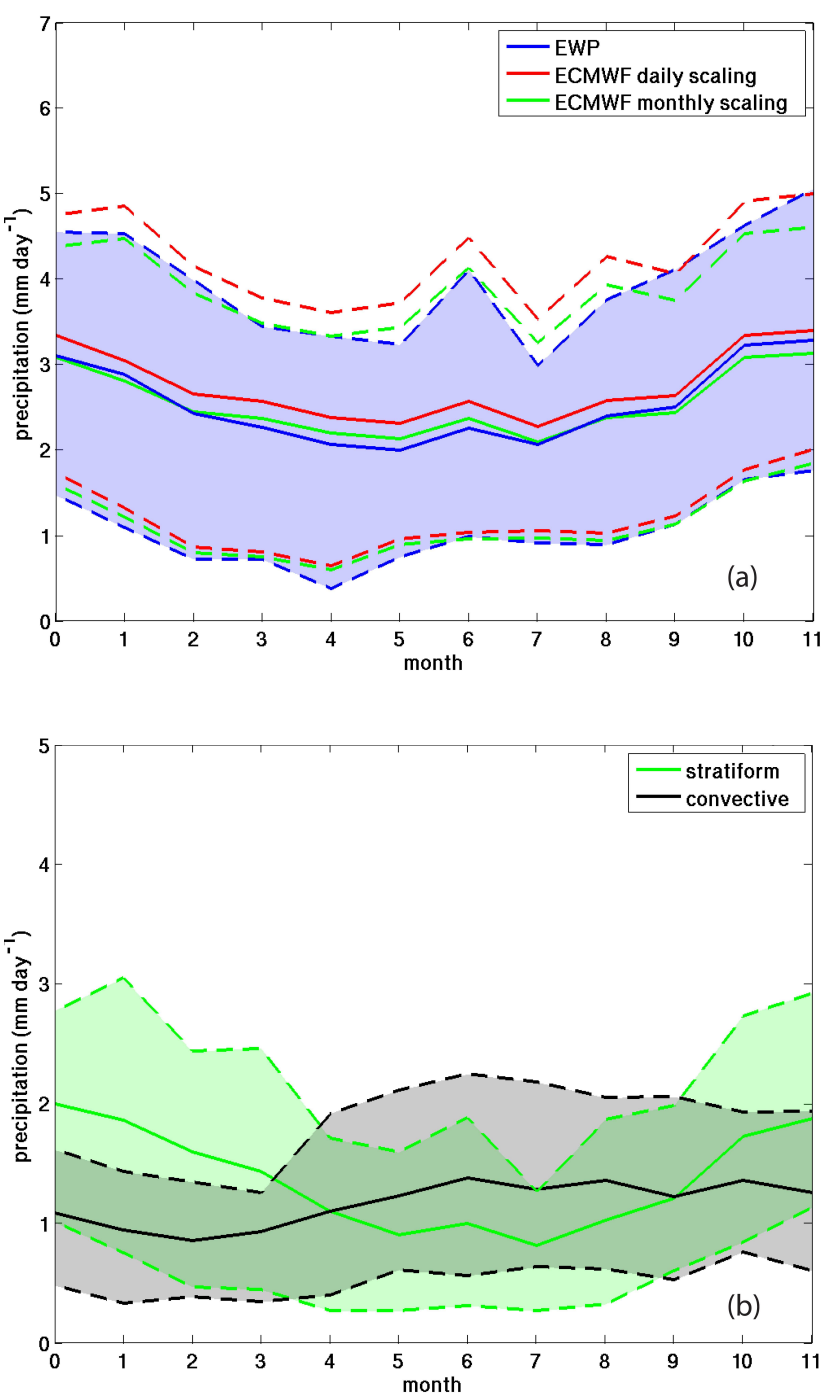

Figure 8. Monthly-mean precipitation rates $(0=\mathrm{Dec})$ for EWP observations and ECMWF reanalysis forecast using data between 1979-2011. a) Comparison between the observations and the rescaled reanalysis forecast. Red represents the best linear fit scaling for daily data $(0.782$ from figure 5a) and green the scaling based on matching the total monthly precipitation amount ( 0.812 from table II). The dashed lines represent the 10/90th percentiles of the accumulations for each calendar month. b) The partition between convective and stratiform (large scale) precipitation in the ECMWF model after applying the daily scaling. Again the shaded area shows the 10/90th percentile range of the data.

to a sampling issue in the observations or that the model's convection parameterisation performs less well than the stratiform precipitation parameterisation.

The underestimation factor for the ERA-Interim forecasts was derived from the total daily precipitation accumulations, without separating the convective and stratiform components. To investigate whether the scaling should be different for the convective and stratiform components, the underestimation in the reanalysis was re-calculated for each ORD with more than $2 \mathrm{~mm}$ day $^{-1}$. This threshold was applied to remove large fluctuations in the ratio ECMWF/EWP for 


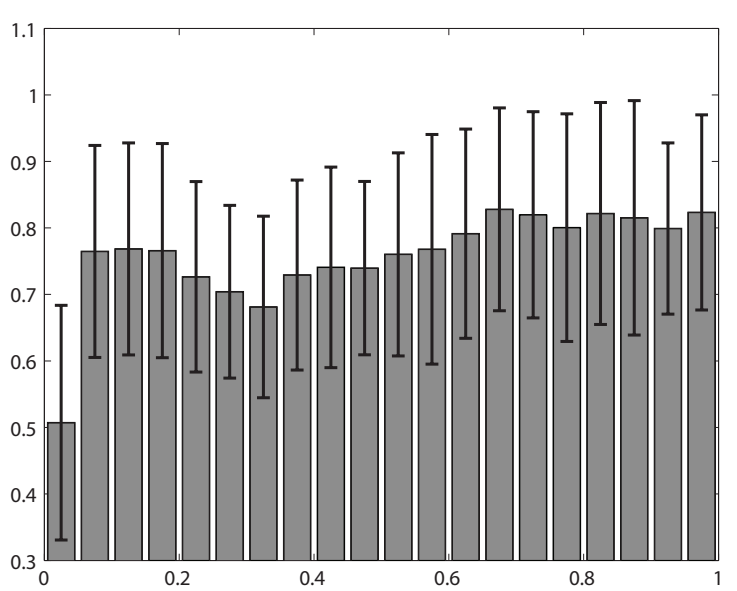

Figure 9. The underestimation of observations by the ERA-Interim precipitation forecasts, binning the forecast data by the fraction of stratiform precipitation across the region. Vertical lines indicated \pm one standard deviation.

small precipitation amounts. The daily accumulations were binned by the stratiform fraction and the scaling factor calculated by a linear fit to a scatter plot of ECMWF versus EWP for all days falling within each bin (Fig. 9). When excluding the first bin, which contains all events with 0 $5 \%$ stratiform precipitation, there is no significant variation of forecast-to-observation ratio with stratiform precipitation fraction. Consequently, the universal scaling factor derived for the total precipitation amount is equally applicable to the separate convection and stratiform components in the reanalysis. The exception is the first bin where the underestimate is much worse. This bin corresponds to convectiondominated conditions and includes 5 times the number of events of all other bins, of which many are low precipitation events around the $2 \mathrm{~mm}$ threshold. It is concluded that the ECMWF model underestimates precipitation in situations with convective showers (light precipitation).

\section{Conclusions}

This study has evaluated 33 years of precipitation forecast data from the ERA-Interim reanalysis using the England and Wales precipitation (EWP) daily time series. The EWP dataset is one of the longest daily records available constructed from a dense raingauge network and the regional estimate has been constructed in such a way as to be insensitive to changes in the observation sites and their representivity Alexander and Jones (2000). EWP has been evaluated thoroughly in the literature (see for example Croxton et al. (2006) who compared EWP with data from independent stations).

The datasets are sufficiently long to characterise the statistical distribution of regional-average precipitation, even in the extreme tails. For example, 120 data points exceed the 99th percentile in the 33-year comparison period. Daily precipitation in the ERA-Interim reanalysis and the EWP observations both closely fit a Weibull distribution, although deviations from the fit are greatest in the tails. The Weibull fits to each dataset overestimate the event frequency in both the light and heavy precipitation tails (in both EWP and the ERA-Interim forecasts). Comparing the distributions shows that they have an indistinguishable shape, but that the ECMWF forecast underestimates the daily observations by an average factor of $22 \%$. Fitting the monthly accumulations indicates a smaller underestimation of $19 \%$ because the ECMWF estimate for heavy daily precipitation accumulations (across the region) is closer to EWP, and these heavier events carry more weight in the monthly accumulation. The slightly non-linear behaviour of forecast underestimation factor with daily precipitation total, is identified in the curvature of a quantile-quantile plot using 33 years of data (figure 5a). Five year subsamples of the data were found to be too short to identify the different behaviour in the high precipitation extremes, including deviation from the Weibull fit and deviation from a single scaling factor for forecasts across the range of intensity.

Spin-up in the ERA-Interim model has only a minor impact on the underestimation of precipitation, since increasing the forecast lead time by 12 hours leads to only a small (3\%) increase in model precipitation estimates. Previous studies have suggested that mountainous areas are an important source of model precipitation underestimation throughout the mid-latitudes (Kobold and Sugelj 2005; Belo-Pereira et al. 2011), mainly due to the coarse resolution of global models. Simpson and Jones (2012) have 
shown that the stations used in the EWP time series were biased toward drier parts of the region, particularly in areas that are more mountainous. As a result any orographic bias in the model is most likely also present in the observations.

The temporal correlation between daily ERA-Interim reanalysis precipitation and EWP observations is roughly constant throughout the year $\left(\mathrm{R}^{2} \approx 0.83\right)$, apart from summer (JJA) when it is slightly lower $\left(\mathrm{R}^{2} \approx 0.78\right)$. The relative importance of the convective and stratiform precipitation fields present in the reanalysis forecast was also investigated. When considering the monthly averages in the reanalysis for both components, it was shown that the stratiform precipitation has a strong seasonal cycle with a minimum in summer, while the convective component shows a slight summer maximum. As a result, the ratio of stratiform to convective precipitation is approximately $2: 1$ in DJF, while it is less than 1:1 in JJA.

The forecast underestimation of total precipitation is mostly independent of the convection:stratiform ratio in the reanalysis, except for a greater underestimation in convection dominated conditions (95-100\% convective fraction), which occurred mainly during summer (JJA) and were associated with light precipitation averaged across the region (isolated convection or convective showers). This may result from problems with the convective parameterisation in the ERA-Interim reanalysis system.

In summary, the statistical distribution of observed daily precipitation is well represented by the ERA-Interim reanalysis model, after correcting by a simple scaling factor. The forecast estimates are slightly closer to the observed regional precipitation for the heaviest events. This indicates that the ERA-Interim reanalysis is a useful tool for studies of seasonal variability in precipitation, extreme rain events and the mechanisms behind them. Hawcroft et al. (2012) has shown that over $70 \%$ of precipitation in northwest Europe is associated with the passage of extratropical cyclones from the North Atlantic stormtrack. Here it has been shown that stratiform precipitation dominates convective precipitation from October to March and is approximately equal to convective precipitation through the summer months, consistent with the importance of cyclones for driving ascent and precipitation over the UK. Therefore, it is expected that the results shown here are relevant to other low lying regions on the maritime edge of continents, downstream of mid-latitude stormtracks.

\section{Acknowledgement}

We thank ECMWF for providing the ERA-Interim reanalysis data. We thank the reviewers for their useful comments, which significantly improved the manuscript.

\section{References}

Alexander LV, Jones PD. 2000. Updated Precipitation Series for the UK and Discussion of Recent Extremes. Atmos. Sci. Lett. 1(2): 142-150, doi: $\{10.1006 /$ asle.2001.0016\}.

Balsamo G, Boussetta S, Lopez P, Ferranti L. 2010. Evaluation of ERA-Interim and ERA-Interim-GPCP-rescaled precipitation over the U.S.A. ERA Rep. Ser. 5: 125.

Bechtold P, Chaboureau J, Beljaars A, Betts A, Kohler M, Miller M, Redelsperger J. 2004. The simulation of the diurnal cycle of convective precipitation over land in a global model. Q. J. R. Meteorol. Soc. 130(604, Part c): 3119-3137, doi:\{10.1256/qj.03. $103\}$.

Belo-Pereira M, Dutra E, Viterbo P. 2011. Evaluation of global precipitation data sets over the Iberian Peninsula. J. Geophys. Res.Atmos. 116, doi: $\{10.1029 / 2010 J D 015481\}$.

Betts A, Ball J, Viterbo P. 2003. Evaluation of the ERA-40 surface water budget and surface temperature for the Mackenzie River basin. J. Hydrometeorol. 4(6): 1194-1211, doi: $\{10.1175 / 1525-7541(2003)$ 004〈1194:EOTESW $\rangle 2.0 . C O ; 2\}$.

Betts AK, Koehler M, Zhang Y. 2009. Comparison of river basin hydrometeorology in ERA-Interim and ERA-40 reanalyses with observations. J. Geophys. Res.-Atmos. 114, doi:\{10.1029/ 2008JD010761\}.

Bosilovich MG, Chen J, Robertson FR, Adler RF. 2008. Evaluation of global precipitation in reanalyses. J. Appl. Meteorol. Climatol. 47(9): 2279-2299, doi:\{10.1175/2008JAMC1921.1\}.

Bosilovich MG, Robertson FR, Chen J. 2011. Global Energy and Water Budgets in MERRA. J. Clim. 24(22): 5721-5739, doi:\{10.1175/ 2011JCLI4175.1\}.

Burgueno A, Martinez M, Lana X, Serra C. 2005. Statistical distributions of the daily rainfall regime in Catalonia (northeastern 
Spain) for the years 1950-2000. Int. J. Climatol. 25(10): 1381-1403, doi: $\{10.1002 /$ joc. 1197$\}$

Croxton PJ, Huber K, Collinson N, Sparks TH. 2006. How well do the Central England Temperature and the England and Wales Precipitation Series represent the climate of the UK? Int. J. Climatol. 26(15): 2287-2292, doi: $\{10.1002 /$ joc.1378\}.

Dai A, Lin X, Hsu KL. 2007. The frequency, intensity, and diurnal cycle of precipitation in surface and satellite observations over low- and mid-latitudes. Clim. Dyn. 29(7-8): 727-744, doi:\{10.1007/ s00382-007-0260-y\}.

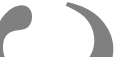
Dee DP, Uppala SM, Simmons AJ, Berrisford P, Poli P, Kobayashi S, Andrae U, Balmaseda MA, Balsamo G, Bauer P, Bechtold P, Beljaars ACM, van de Berg L, Bidlot J, Bormann N, Delsol C, Dragani R, Fuentes M, Geer AJ, Haimberger L, Healy SB, Hersbach H, Holm EV, Isaksen L, Kallberg P, Koehler M, Matricardi M, McNally AP, Monge-Sanz BM, Morcrette JJ, Park BK, Peubey C, de Rosnay P, Tavolato C, Thepaut JN, Vitart F. 2011. The ERA-Interim reanalysis: configuration and performance of the data assimilation system. $Q$. J. R. Meteorol. Soc. 137(656, Part a): 553-597, doi:\{10.1002/qj.828\}.

Dinku T, Ceccato P, Grover-Kopec E, Lemma M, Connor SJ, Ropelewski CF. 2007. Validation of satellite rainfall products over East Africa's complex topography. Int. J. Remote Sens. 28(7-8): 1503-1526, doi: $\{10.1080 / 01431160600954688\}$.

Ebert EE, Janowiak JE, Kidd C. 2007. Comparison of near-real-time precipitation estimates from satellite observations and numerical models. Bull. Amer. Meteorol. Soc. 88(1): 47+, doi: $\{10.1175 /$ BAMS-88-1-47\}.

Gregory JM, Jones PD, Wigley TML. 1991. Precipitation in Britain: An analysis of area-average data updated to 1989. Int. J. Climatol. 11(3): 331-345, doi:10.1002/joc.3370110308.

Hand W, Fox N, Collier C. 2004. A study of twentieth-century extreme rainfall events in the United Kingdom with implications for forecasting. Meteorol. Appl. 11(1): 15-31, doi: $\{10.1017 /$ S1350482703001117\}.

Hawcroft MK, Shaffrey LC, Hodges KI, Dacre HF. 2012. How much Northern Hemisphere precipitation is associated with extratropical cyclones? Geophysical Research Letters 39(24), doi:10.1029/ 2012 GL053866.

Kistler R, Kalnay E, Collins W, Saha S, White G, Woollen J, Chelliah M, Ebisuzaki W, Kanamitsu M, Kousky V, van den Dool H, Jenne R, Fiorino M. 2001. The NCEP-NCAR 50-year reanalysis: Monthly means CD-ROM and documentation. Bull. Amer. Meteorol. Soc. 82(2): 247-267, doi: $\{10.1175 / 1520-0477(2001)$ 082 $\langle 0247:$ TNNYRM $\rangle$ 2.3.CO;2\}.
Kobold M, Sugelj K. 2005. Precipitation forecasts and their uncertainty as input into hydrological models. Hydrol. Earth Syst. Sci. 9(4, SI): 322-332. International Conference on Advances in Flood Forecasting in Europe, Rotterdam, Netherlands, Mar 03-05, 2003.

Maraun D, Osborn TJ, Gillett NP. 2008. United Kingdom daily precipitation intensity: improved early data, error estimates and an update from 2000 to 2006. Int. J. Climatol. 28(6): 833-842, doi: $\{10.1002 /$ joc. 1672$\}$.

Mills T. 2005. Modelling precipitation trends in England and wales. Meteorol. Appl. 12(2): 169-176, doi:\{10.1017/ S1350482705001611\}.

Osborn T, Hulme M, Jones P, Basnett T. 2000. Observed trends in the daily intensity of United Kingdom precipitation. Int. J. Climatol. 20(4): 347-364, doi:\{10.1002/(SICI)1097-0088(20000330)20: 4〈347::AID-JOC475 $\rangle 3.0 . \mathrm{CO} ; 2-\mathrm{C}\}$.

Poccard I, Janicot S, Camberlin P. 2000. Comparison of rainfall structures between NCEP/NCAR reanalyses and observed data over tropical Africa. Clim. Dyn. 16(12): 897-915, doi:\{10.1007/ s003820000087\}.

Romanou A, Tselioudis G, Zerefos CS, Clayson CA, Curry JA, Andersson A. 2010. Evaporation-Precipitation Variability over the Mediterranean and the Black Seas from Satellite and Reanalysis Estimates. J. Clim. 23(19): 5268-5287, doi:\{10.1175/ 2010JCLI3525.1\}.

Sapiano MRP, Smith TM, Arkin PA. 2008. A new merged analysis of precipitation utilizing satellite and reanalysis data. J. Geophys. Res.Atmos. 113, doi: $\{10.1029 / 2008 J D 010310\}$.

Simmons AJ, Willett KM, Jones PD, Thorne PW, Dee DP. 2010. Lowfrequency variations in surface atmospheric humidity, temperature, and precipitation: Inferences from reanalyses and monthly gridded observational data sets. J. Geophys. Res.-Atmos. 115, doi:\{10.1029/ 2009JD012442\}.

Simpson IR, Jones PD. 2012. Updated precipitation series for the UK derived from Met Office gridded data. Int. J. Climatol. 32(15): 22712282, doi: $\{10.1002 /$ joc.3397\}.

Szczypta C, Calvet JC, Albergel C, Balsamo G, Boussetta S, Carrer D, Lafont S, Meurey C. 2011. Verification of the new ECMWF ERAInterim reanalysis over France. Hydrol. Earth Syst. Sci. 15(2): 647666, doi: $\{10.5194 /$ hess-15-647-2011\}.

Tiedtke M. 1989. A comprehensive mass flux scheme for cumulus parameterization in large-scale models. Mon. Weather Rev. 117(8): 1779-1800, doi:\{10.1175/1520-0493(1989)117〈1779:ACMFSF $\rangle 2$. $0 . \mathrm{CO} ; 2\}$.

Tiedtke M. 1993. Representation of clouds in large-scale models. Mon. Weather Rev. 121(11): 3040-3061, doi:\{10.1175/1520-0493(1993)

This article is protected by copyright. All rights reserved. 
121〈3040:ROCILS $\rangle 2.0 . C O ; 2\}$.

Tompkins AM, Gierens K, Radel G. 2007. Ice supersaturation in the ECMWF integrated forecast system. Q. J. R. Meteorol. Soc. 133(622, Part a): 53-63, doi:\{10.1002/qj.14\}.

Trenberth K, Guillemot C. 1998. Evaluation of the atmospheric moisture and hydrological cycle in the NCEP/NCAR reanalyses. Clim. Dyn. 14(3): 213-231, doi: $\{10.1007 / \mathrm{s} 003820050219\}$.

Wigley TML, Briffa KR, Jones PD. 1984a. On the average value of correlated time series, with applications in dendroclimatology and hydrometeorology. J. Clim. Appl. Meteorol. 23: 201-213, doi: 10.1175/1520-0450(1984)023〈0201:OTAVOC $\rangle 2.0 . C O ; 2$.

Wigley TML, Jones PD. 1987. England and Wales precipitation: A discussion of recent changes in variability and an update to 1985 . J. Climatol. 7(3): 231-246, doi:10.1002/joc.3370070304.

Wigley TML, Lough JM, Jones PD. 1984b. Spatial patterns of precipitation in England and Wales and a revised, homogeneous England and Wales precipitation series. J. Climatol. 4(1): 1-25, doi: 10.1002/joc.3370040102.

Yilmaz K, Hogue T, Hsu K, Sorooshian S, Gupta H, Wagener T. 2005. Intercomparison of rain gauge, radar, and satellite-based precipitation estimates with emphasis on hydrologic forecasting. $J$. Hydrometeorol. 6(4): 497-517, doi:\{10.1175/JHM431.1\}.

Zolina O, Kapala A, Simmer C, Gulev S. 2004. Analysis of extreme precipitation over Europe from different reanalyses: a comparative assessment. Glob. Planet. Change 44(1-4): 129-161, doi: \{10.1016/j. gloplacha.2004.06.009\}.

This article is protected by copyright. All rights reserved. 